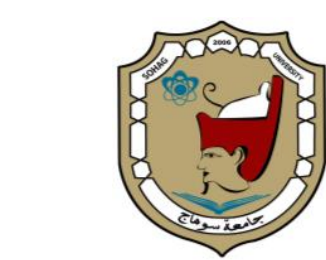

Sohag University
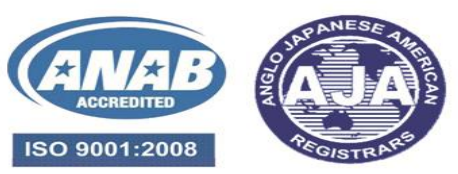

Sohag Medical Journal

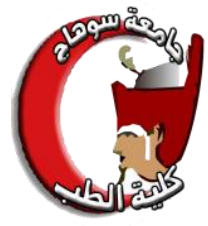

Faculty of Medicine

\title{
The usefulness of Platelet indices in the diagnosis of different causes of thrombocytopenia
}

\section{Marwa Zanaty Elsayed ${ }^{1}$, Lotfy Hamed Abo-Dahab ${ }^{1}$, Eman H Salama$^{2}$, Hamdy S Mohammed ${ }^{1}$}

1- internal medicine department, Faculty of Medicine, Sohag University

2- clinical pathology department, Faculty of Medicine, Sohag University

\begin{abstract}
Thrombocytopenia is diagnosed when the platelet number is less than the lower normal limit (ie, $<150,000 / \mathrm{microL}\left[150 \times 10^{9} / \mathrm{L}\right]$ for adults, can occur because of lower platelet production (hypo-productive) or increased platelet consumption/destruction (hyper-destructive) and the differentiation between both forms is important. platelet indices as mean platelet volume (MPV), platelet crit (PCT), and (PDW) can help identify both hyper-destructive and hypo-productive thrombocytopenia, obviating the need for a bone marrow test. The study included 80 individuals, each of whom had their $\mathrm{CBC}$ and platelet indices conducted.

Objective: the main objective of this thesis is to see how effective platelet indices are at distinguishing between the two types of thrombocytopenia.

Results: The study revealed that patients in the hyper-destructive thrombocytopenic group were predominantly females, meanwhile, patients in the hypo-productive thrombocytopenia group were predominantly males. WBCs, reticulocyte count, hemoglobin level, and platelet indices (MPV, PCT, PDW) were much higher in the hyper-destructive thrombocytopenia group.
\end{abstract}

Conclusion: Platelet indices can help differentiate both hyper-destructive and hypoproductive thrombocytopenia, obviating the need for a bone marrow test.

Keywords: Hyper-destructive thrombocytopenia; hypo-productive thrombocytopenia; platelet indices.

\section{Introduction}

A platelet number fewer than the normal cutoff threshold, which in adults is $150,000 / \mathrm{microL}$, is referred to as thrombocytopenia $^{(1)}$. In medical practice, thrombocytopenia seems to be the most prevalent reason for a hematologic consultation, which is also one of the first most life-threatening illnesses ${ }^{(2)}$. Maybe because of a decrease in platelet synthesis (hypo-productive) or acceleration in platelet consumption /destruction (hyper-destructive) thrombocytepenia $^{(3)}$. Hematological malignancies (leukemia, myeloma, myelody- splasia, and myelofibrosis), cytotoxic drugs or radiotherapy, infections (human immunodeficiency virus (HIV), Cytomegalovirus (CMV), hepatitis B, and $\mathrm{C}$ ), aplastic a-nd megaloblastic anemia, and generalized bone marrow failures are all examples of hypo-productive thrombocyteopenia ${ }^{(4)}$.

Idiopathic/primary autoimmune (ITP), Secondary (systemic lupus erythematosus, chronic lymphocytic leukemia, lymphoma), Infections (HIV, hepatitis $\mathrm{B}$, and C, malaria), Drug-induced (rifampicin, penicillin, sulphonamides, $\mathrm{He}-$ 
parin, quinine), and disseminated intravascular hemolysis (DIC) are all examples of hyper-destructive thrombocytepenia, platelet indices as mean platelet volume (MPV), platelet crit (PCT), and (PDW) can help identify both hyper-destructive and hypo-productive thrombocytopenia, obviating the need for a bone marrow test ${ }^{(2)}$.

\section{Materials and Methods}

Time frame: between (January 2018August 2019).

Study population: This study was conducted on 80 consecutive patients, fulfilling inclusion and exclusion criteria, who attended at internal medicine department hematology unit, Sohag university hospital during the study period.

\section{Inclusion criteria:}

1. Age 18 years old or above.

2. Idiopathic thrombocytopenic purpura "ITP", disseminated intravascular coagulation "DIC" patients with thrombocytopenia and platelet number less than $150 \times 10^{9} / \mathrm{L}$.

3. Patients newly diagnosed with aplastic anemia, myelodysplastic syndrome "MDS", leukemia with thrombocytopenia.

\section{Exclusion criteria:}

1. ITP patients with a platelet count 150,000 or more on treatment.

2. Patients under the age of 18 years old.

3. Patients who received platelet transfusion. The

The included patients were classified into two groups:

a) Patients with hyper-destructive thrombocytopenia: included 36 patients newly diagnosed with ITP, DIC, and TTP.

b) Patients with hypo-productive thrombocytopenia: included 44 patients newly diagnosed with aplastic anemia, MDS, and leukemias.

\section{Methods}

Full history was taken from all participants including age, gender, diabetic or hypertensive, special habits as well as a history of bleeding tendency and chronic diseases.

Blood samples for complete blood count $(\mathrm{CBC})$ analysis and platelet indices were collected into $5 \mathrm{ml}$ EDTA anticoagulated tubes. Analysis was done using Cell dyne ruby based on the manufacturer's protocol. All blood samples were analyzed in less than $4 \mathrm{~h}$ of blood collection.

\section{Statistical analysis}

Data were collected, revised, coded, tabulated, and analyzed using STATA version 14.2 (Stata Statistical Software: Release 14.2 College Station, TX: StataCorp LP). Quantitative data were presented as mean, standard deviationns, and ranges. Meanwhile, qualitative variables were presented as numbers and percentages. The appropriate test of significance was conducted, and the Spearman correlation test was used to test for correlation between continuous variables. The confidence interval was set to $95 \%$ and the margin of error accepted was set to $5 \%$. So, the p-value was considered significant at the level of $<0.05$.

\section{Results}

A very highly statistically significant difference $(\mathrm{p}<0.0001)$ was found between both groups as regards gender with $61.22 \%$ of females being in the hyper-destructive thrombocytopenia $\mathrm{g}$ roup and $80.65 \%$ of males being in the hypo-productive thrombocytopenia group. Meanwhile, no statistically significant differences were found between both groups as regards age, diabetics, hypertensive, but there was a statistically significant difference between both groups as regards bleeding score (Table 1). 
SOHAG MEDICAL JOURNAL

Vol. 25 No. 3 Sept 2021
The usefulness of Platelet indices in the diagnosis

Marwa Zanaty Elsayed

Table (1): Comparison between hyper-destructive and hypo-productive thrombocytopenia groups as regards clinical characteristics:

\begin{tabular}{|c|c|c|c|}
\hline Variable & $\begin{array}{c}\text { Hyper-destructive } \\
\text { thrombocytopenia } \\
(\mathrm{N}=36)\end{array}$ & $\begin{array}{c}\text { Hypo-productive } \\
\text { thrombocytopenia } \\
(\mathrm{N}=44)\end{array}$ & P-Value \\
\hline $\begin{array}{l}\text { Age }(\text { years }) \\
\text { Mean } \pm \text { SD } \\
\text { Median (range) }\end{array}$ & $\begin{array}{c}37.64 \pm 14.50 \\
39(17-70)\end{array}$ & $\begin{array}{l}36.43 \pm 14.51 \\
39.5(13-65)\end{array}$ & 0.75 \\
\hline $\begin{array}{l}\text { Gender } \\
\text { Female } \\
\text { Male }\end{array}$ & $\begin{array}{c}30(78.75 \%) \\
6(22.25 \%)\end{array}$ & $\begin{array}{l}19(20.35 \%) \\
25(80.65 \%)\end{array}$ & $<0.0001$ \\
\hline $\begin{array}{l}\text { Diabetes } \\
\text { Diabetic } \\
\text { Non-diabetic } \\
\end{array}$ & $\begin{array}{c}9(24.28 \%) \\
27(75.72 \%)\end{array}$ & $\begin{array}{l}12(28.80 \%) \\
28(71.20 \%)\end{array}$ & 0.21 \\
\hline $\begin{array}{l}\text { Bleeding score } \\
\text { Mean } \pm \text { SD } \\
\text { Median (range) } \\
\end{array}$ & $\begin{array}{c}1.08 \pm 0.65 \\
1(0: 3) \\
\end{array}$ & $\begin{array}{c}2.57 \pm 1.38 \\
3(0: 4) \\
\end{array}$ & 0.0001 \\
\hline $\begin{array}{l}\text { Hypertension } \\
\text { Hypertensive } \\
\text { Non-Hypertensive }\end{array}$ & $\begin{array}{c}5(15.60 \%) \\
31(84.40 \%)\end{array}$ & $\begin{array}{c}8(23.25 \%) \\
36(76.75 \%)\end{array}$ & 0.30 \\
\hline
\end{tabular}

Highly statistically significant differences were found between both groups as regards reticulocyte count as well as hemoglobin level with higher mean values in the hyperdestructive thrombocytopenic group. Meanwhile, no statistically significant differences were found between both groups as regards MCV or coagulation profile (Table 2).

Table (2): Comparison between hyper-destructive and hypo-productive thrombocytopenia groups as regards laboratory findings:

\begin{tabular}{|c|c|c|c|}
\hline Variable & $\begin{array}{c}\text { Hyper-destructive } \\
\text { thrombocytopenia } \\
(\mathrm{N}=36)\end{array}$ & $\begin{array}{c}\text { Hypo-productive } \\
\text { thrombocytopenia } \\
(\mathrm{N}=\mathbf{4 4 )}\end{array}$ & P-value \\
\hline $\begin{array}{l}\text { WBCs } \\
\text { Mean } \pm \text { SD } \\
\text { Median (range) } \\
\end{array}$ & $\begin{array}{l}12.48 \pm 16.00 \\
7.75(1.9-80)\end{array}$ & $\begin{array}{c}8.60 \pm 11.51 \\
4.3(1.2-9.3) \\
\end{array}$ & 0.73 \\
\hline $\begin{array}{l}\text { Hemoglobin } \\
\text { Mean } \pm \text { SD } \\
\text { Median (range) }\end{array}$ & $\begin{array}{c}9.38 \pm 2.22 \\
10(4.5-12.2)\end{array}$ & $\begin{array}{c}7.13 \pm 1.84 \\
7.2(2.8-11)\end{array}$ & $<0.0001$ \\
\hline $\begin{array}{l}\text { Reticulocyte } \\
\text { Mean } \pm \text { SD } \\
\text { Median (range) }\end{array}$ & $\begin{array}{l}1.40 \pm 1.24 \\
1(0.01-6)\end{array}$ & $\begin{array}{c}0.91 \pm 0.43 \\
0.85(0.4-2)\end{array}$ & 0.005 \\
\hline $\begin{array}{l}\text { MCV } \\
\text { Mean } \pm \text { SD } \\
\text { Median (range) } \\
\end{array}$ & $\begin{array}{l}83.58 \pm 7.51 \\
82(74-104) \\
\end{array}$ & $\begin{array}{c}87.55 \pm 10.12 \\
87(64.5-110) \\
\end{array}$ & 0.54 \\
\hline $\begin{array}{l}\text { Platelet } \\
\text { Mean } \pm \text { SD } \\
\text { Median (range) }\end{array}$ & $\begin{array}{l}38.52 \pm 23.51 \\
30(9.4: 107)\end{array}$ & $\begin{array}{c}34.92 \pm 20.64 \\
30(10.1: 91.5)\end{array}$ & 0.59 \\
\hline $\begin{array}{l}\text { Coagulation profile } \\
\text { Normal } \\
\text { Prolonged INR, PT }\end{array}$ & $\begin{array}{c}34(94.44 \%) \\
2(5.56 \%)\end{array}$ & $\begin{array}{c}44(100 \%) \\
0\end{array}$ & 0.20 \\
\hline
\end{tabular}

No significant statistical difference was observed between both groups as regards platelet count. Meanwhile, platelet indices mean values (MPV, PCT, PDW) were significantly higher in the hyper-destructive thrombocytopenia group compared to the hypo-productive group (Table 3). 
SOHAG MEDICAL JOURNAL

Vol. 25 No. 3 Sept 2021
The usefulness of Platelet indices in the diagnosis

Marwa Zanaty Elsayed

Table (3): Comparison between hyper-destructive and hypo-productive thrombocyteopenia groups as regards platelet count and indices:

\begin{tabular}{|l|c|c|c|}
\hline Variable & $\begin{array}{c}\text { Hyper-destructive thrombocytopenia } \\
\mathbf{( N = 3 6 )}\end{array}$ & $\begin{array}{c}\text { Hypo-productive } \\
\text { thrombocytopenia } \\
\mathbf{( N = 4 4 )}\end{array}$ & P-Value \\
\hline Platelets & $38.52 \pm 23.51$ & $34.92 \pm 20.64$ & 0.59 \\
Mean \pm SD & $30(9.4-107)$ & $30(10.1-91.5)$ & \\
Median (range) & $12.02 \pm 2.41$ & $7.65 \pm 1.96$ & $<0.0001$ \\
\hline MPV & $12(8-16)$ & $7(6-15.4)$ & \\
Mean \pm SD & $0.04 \pm 0.02$ & $0.03 \pm 0.02$ & 0.0001 \\
Median (range) & $0.04(0.02-0.10)$ & $0.02(0.01-0.08)$ & \\
\hline PCT & $24.35 \pm 1.61$ & $19.23 \pm 2.56$ & $<0.0001$ \\
Mean \pm SD & $24.5(21.3-27)$ & $19.75(9-23)$ & \\
Median (range) & & & \\
\hline PDW & & & \\
Mean \pm SD & & & \\
Median (range) & &
\end{tabular}

Table (4): B.M aspiration among thrombocytopenic patients:

\begin{tabular}{|l|c|}
\hline Variable & Number (percent) \\
\hline Hyper destructive thrombocytopenic group & $\mathbf{3 6}(\mathbf{4 5 . 0 0 \% )}$ \\
\hline ITP & $31(38.75 \%)$ \\
\hline TTP & $3(3.75 \%)$ \\
\hline DIC & $2(2.50 \%)$ \\
\hline Hypo productive thrombocytopenic group & $\mathbf{4 4}(\mathbf{5 5 . 0 0 \%})$ \\
\hline ALL & $2(2.50 \%)$ \\
\hline AML & $11(13.75 \%)$ \\
\hline Aplastic anemia & $13(16.25 \%)$ \\
\hline CML & $3(3.75 \%)$ \\
\hline MDS & $15(18.75 \%)$ \\
\hline
\end{tabular}

A significant inverse relationship was found between MPV, and platelet counts in the hyper-destructive thrombocytopenic group (Figure 1).

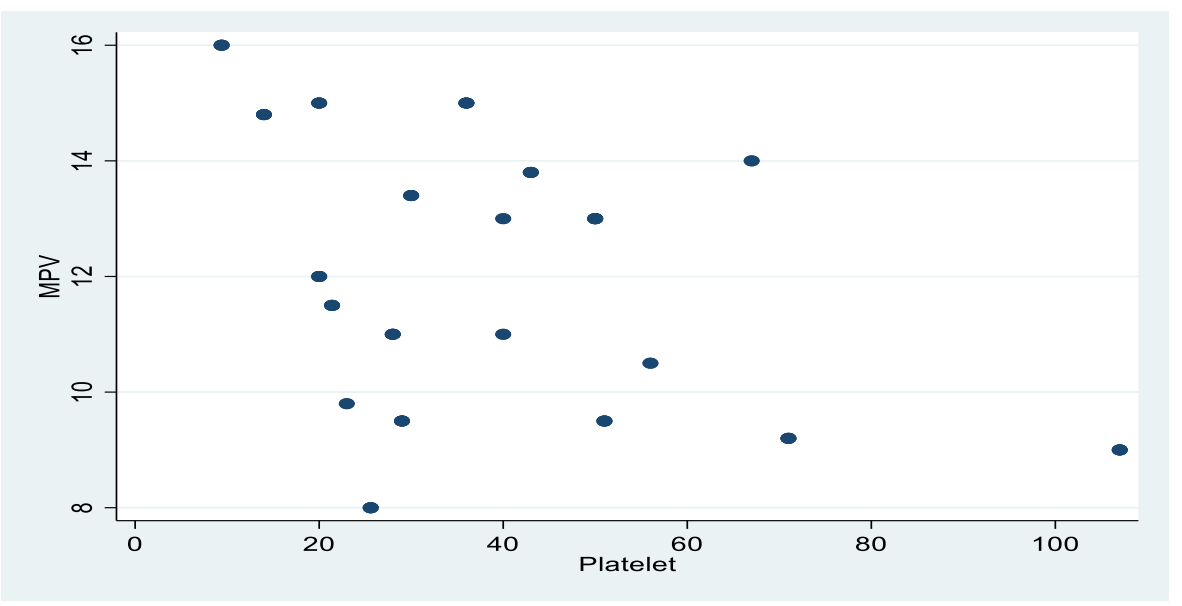

Figure (1): Correlation between platelet count and MPV in hyper-destructive thrombocytopenia $(r=-0.45, p=0.007)$

Meanwhile, a significant linear correlation was found between platelet count and PCT in both hyper-destructive and hypo-productive thrombocytopenia (figure 2, figure 3 ). 


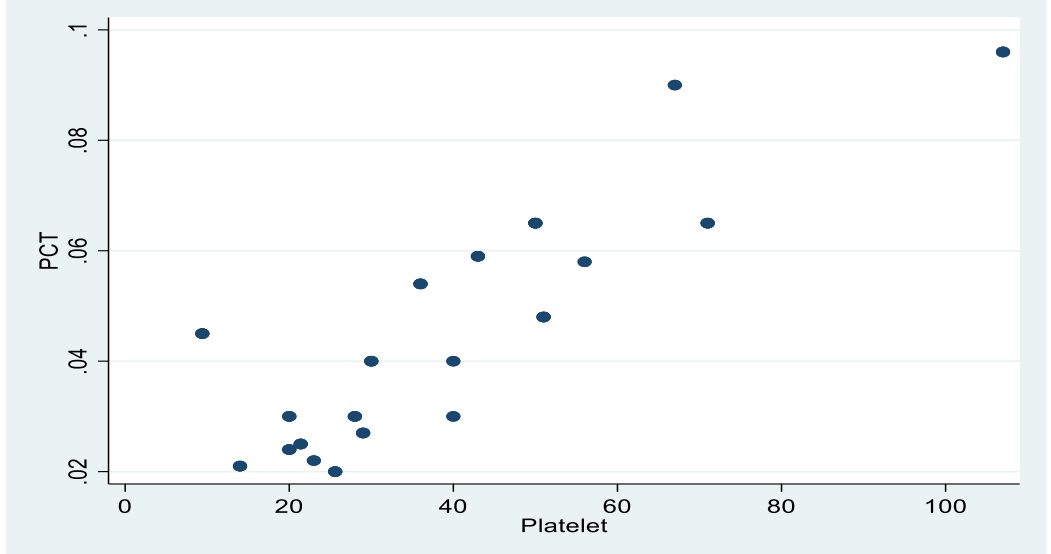

Figure (2): Correlation between platelet count and PCT in hyper-destructive thrombocytopenia $(r=0.80, \mathrm{p}<0.0001)$

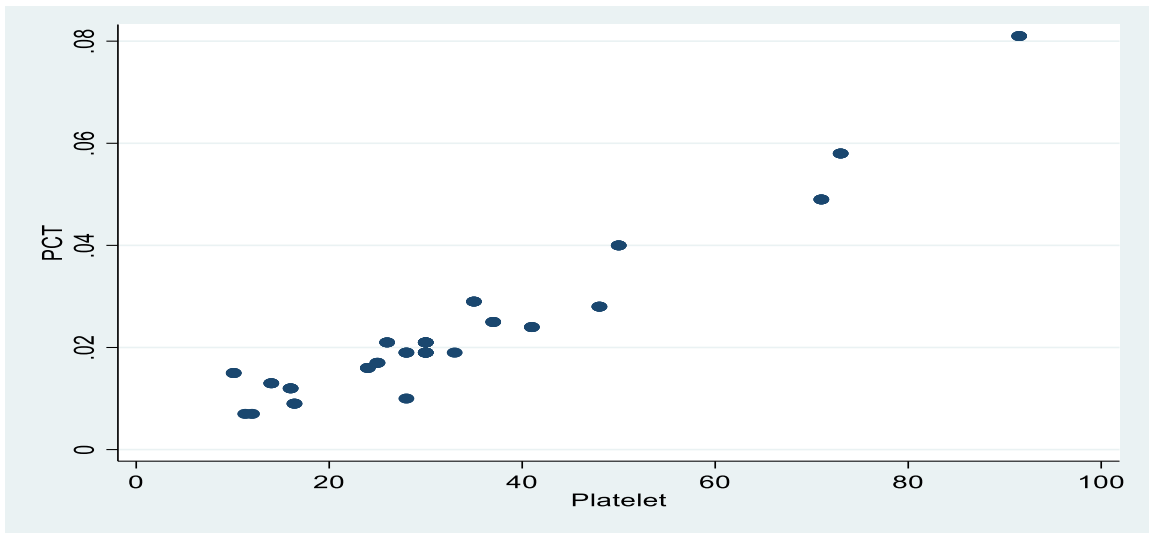

Figure (3): Correlation between platelet count and PCT in hypo-productive thrombocytopenia $(\mathrm{r}=0.93, \mathrm{p}<0.0001)$

\section{Discussion}

It is important to differentiate between thrombocytopenia resulting from hypoproduction of platelets from that resuling from hyper-destruction and to know which is more dominant ${ }^{(5)}$. Measurement of the platelet indices. An automated hematological analyzer is easy, affordably priced, rapid test, and eliminates examiner bias ${ }^{(6,7)}$, It also avoids variations in platelet size caused by increased adhesion strength with flattening and increasing size of the platelets on the glass slide throughout blood smears, as well as changes caused by the delayed time between venipuncture and smear preparation ${ }^{(8)}$. This study revealed that patients in the hyper-destructive thrombocytopenic g- roup were predominantly females; whereas patients in the hypo-productive thrombocytopenic group were predominantly males and similar findings were previously reported ${ }^{(9)}$. This gender distribution could be attributed to epidemiological differences in the incidence and prevalence of chronic ITP, which is more prevalent in females (in women of childbearing age) compared to males with a ratio of $2-3$ to $1^{(10,11)}$, while CML is more common in old ages and males than females with ratios of $1.5-1.8$ to $1^{(12,13)}$.

Higher hemoglobin levels were reported in this research. In the hyperdestructive thrombocytopenia group with no difference between both gro- 
ups as regards the MCV and this was like findings in a previous study ${ }^{(2)}$.

No significant statistical difference wa$\mathrm{s}$ found between the two groups as regards the platelet count in the current study and this finding was reported in previous studies $^{(2,9)}$

The current study found that platelet indices (MPV, PCT, and PDW) were significantly higher in the group with hyper destructive thrombocytopenia when compared to the hypo-productive group. Newly generated platelets are larger than circulating platelets, which explains the high MPV in ITP, which tends to decrease in size with age in the circulation over 7-10 days platelet life span. Thus, in patients with hyperdestructive thrombocytopenia, the MP$\mathrm{V}$ is increased, reflecting active bone marrow compensation with the release of young platelets ${ }^{(14,15)}$. The increased bone marrow synthesis of platelet is also associated with heterogenic populations of platelet (anisocytosis) resulting in higher PDW in hyper-destructive thrombocytopenia ${ }^{(16)}$. MPV and PDW were observed to be significantly higher in the ITP-group when compared to the non-ITP group in many previous studies ${ }^{(2,17,18)}$. Also, similar findings were reported by $X u$ et al. ${ }^{(19)}$ when comparing PDW between ITP group with the bone marrow dysfunction group, in whom higher PDW results were obtained compared with the ITP group and they commented that this was consistent with a significant bone marrow dysplasia. However, conflicting results were reported by Elsewefy et $a l^{(20)}$. as they found that there was no significant difference between both groups (ITP patients' group and hypo productive thrombocytopenia patients), regarding PDW. Both mean platelet volume (MPV) and platelet distribution (PDW) width are accurate tests for detecting ITP. They are also considered assays with 100 pe- rcent sensitivity and specificity when diagnosing $\operatorname{ITP}^{(16,21)}$.

PCT is not regarded as a good index for distinguishing between both groups of thrombocytopenia because it is derived from PDW multiplied by platelet number, it is influenced by decreases in platelet number ${ }^{(22)}$.

The current study revealed a substantial inverse association between platelet number and MPV, in addition to a significant linear correlation between PCT and platelet number in both thrombocytopenic groups. A prior study reported a significant negative correlation between platelet number and platelet indices in ITP patients ${ }^{(9)}$.

Katti et al. reported conflicting results $^{(23)}$, in the hypo-production group, they discovered a significant linear correlation between platelet count and MPV, as well as an inverse relationnship between platelet count and PDW in the hyper-destruction group. This discrepancy in results could be due to co-existing diseases that influence platelet indices.

\section{Conclusion}

Platelet indices can help differentiate both hyper-destructive and hypo-productive thrombocytopenia, obviating the need for a bone marrow test.

\section{Recommendations}

Platelet indices should be given more attention and concern in the evaluation of patients with thrombocytopenia.

\section{Ethical approval}

The study protocol received approval from Sohag university hospital, faculty of medicine. Administrative approval and official permissions were obtained before data collection. Informed consent was obtained from patients included in the study following a guarantee of data confidentiality to them. 


\section{References}

1. Williamson DR, Albert M, HeelsAnsdell D, Arnold DM, Lauzier F, Zarychanski R, et al. Thrombocytopenia in critically ill patients receiving thromboprophylaxis: frequency, risk factors, and outcomes. 2013;144(4):1207-15.

2. Jumaa Khaleel K, Anwer Ahmed AJKJoM. Platelet indices and their relations to platelet count in hypoproductive and hyper-destructive Thrombocytopenia. 2014;7(2):1952-8.

3. Islam S, Islam M, Ahmed M, Aziz M, Begum MJHTIJ. Role of mean platelet volume (MPV), platelet distribution width (PDW), and platelet large cell ratio (P-LCR) value in the diagnosis of immune thrombocytopenic purpura. 2016;2(2):1-5.

4. Zulfania Z, Hayat $H$, Mahmood R, Bukhari AA, Ihtesham Y, Rasool UJPJOP. COMPARISON OF PLATELET INDICES IN HYPERPRODUCTIVE AND HYPER DESTRUCTIVE THROMBOCYTOPENIA. 2021;17(2):3-6.

5. George JN, Woolf SH, Raskob GE, Wasser JS, Aledort LM, Ballem PJ, et al. Idiopathic thrombocytopenic purpura: a practice guideline developed by explicit methods for the American Society of Hematology. 1996;88(1):340.

6. Beyan C, Kaptan K, Ifran AJJot, thrombolysis. Platelet count, mean platelet volume, platelet distribution width, and plateletcrit do not correlate with optical platelet aggegation responses in healthy volunteers. 2006;22(3):161-4.

7. Borkataky S, Jain R, Gupta R, Singh S, Krishan G, Gupta K, et al. Role of platelet volume indices in the differential diagnosis of thrombocytopenia: a simple and inexpensive method. 2009;14(3):182-6.

8. Nelson III RB, Kehl DJC. Electronically determined platelet indices in thrombocytopenic patients. 1981;48(4):954-6.

9. Negash M, Tsegaye AJBh. Diagnostic predictive value of platelet indices for discriminating hypo productive versus immune thrombocytopenic purpura in patients attending a tertiary care teaching hospital in Addis Ababa, Ethiopia. 2016;16(1):1-8.

10.Gernsheimer TJEJoH. Epidemiology and pathophysiology of immune thrombocytopenic purpura. 2008;80:38.

11. Marieke Schoonen W, Kucera G, Coalson J, Li L, Rutstein M, Mowat F, et al. Epidemiology of immune thrombocytopenic purpura in the General Practice Research Database. 2009;145(2):235-44.

12.Rodriguez-Abreu D, Bordoni A, Zucca EJAoo. Epidemiology of hematological malignancies. 2007; 18:i3-i8.

13.Siegel RJCCjC. NaiShadham d, Jemal a. Cancer statistics, 2012. 2012;62(1):10-29.

14. Kottke-Marchant K, Corcoran GJAop, medicine 1 . The laboratory diagnosis of platelet disorders: an algorithmic approach. 2002;126(2):133-46.

15.Numbenjapon $\mathrm{T}$, Mahapo $\mathrm{N}$, Pornvipavee R, Sriswasdi C, Mongkonsritragoon W, Leelasiri A, et al. A prospective evaluation of normal mean platelet volume in discriminating hyper destructive thrombocytopenia from hyperproductive thrombocytopenia. 2008;30(5):408-14.

16.Rajantie J, Javela K, Joutsi-Korhonen L, Kekomäki RJEjoh. Chronic thrombocytopenia of childhood: use of non-invasive methods in clinical evaluation. 2004;72(4):268-72.

17. Shah AR, Chaudhari SN, Shah MHJH. Role of platelet parameters in diagnosing various clinical conditions. 2011;89:11-3.

18. Mowafy NM, Elkeiy MT, Khedr MA$\mathrm{H}$, Masselihy MHGJTEJoHM. Role of Platelet Indices and Antiplatelet Antibody in Differentiating Immune Thrombocytopenic Purpura from Other Causes of Thrombocytopenia. 2019;74(8):1732-6.

19.Xu R-L, Zheng Z-J, Ma Y-J, Hu Y-P, Zhuang S-HJE, medicine $t$. Platelet volume indices have low diagnostic efficiency for predicting bone marrow 
failure in thrombocytopenic patients. 2013;5(1):209-14.

20.Elsewefy D, Farweez B, Ibrahim RJTEJoH. Platelet indices: consideration in thrombocytopenia. 2014;39(3): 134 .

21.Ntaios G, Papadopoulos A, Chatzinikolaou A, Sauli Z, Karalazou $P$, Kaiafa $G$, et al. Increased values of mean platelet volume and platelet size deviation width may provide a safe positive diagnosis of idiopathic thrombocytopenic purpura. 2008;119(3):173-7.

22. Chandrashekar VJJoH. Plateletcrit as a screening tool for detection of platelet quantitative disorders. 2013;2(1):22-6.

23. Katti TV, Mhetre SC, Annigeri C. How far are the platelet indices mirror image of the mechanism of thrombocytopenia-mystery still remains. 2014. 